\title{
Serum creatine kinase after intramuscular injections
}

\author{
F. Konikoff, J. Halevy and E. Theodor \\ Department of Internal Medicine E, Beilinson Medical Center, Petah-Tiqva and Tel Aviv University Sackler School \\ of Medicine, Israel.
}

\begin{abstract}
Summary: Serum creatine kinase (CK) activity was measured after intramuscular injections in 44 patients hospitalized for non-cardiac reasons. The drugs injected were: diazepam, dipyrone, metoclopramide, meperidine, pentazocine and procaine penicillin. Only 3 out of 44 patients (7\%) demonstrated significant elevation of $\mathrm{CK}$ levels following the intramuscular injections. In these 3 patients the elevation was mainly due to a rise of the MM-isoenzyme fraction with MB levels increased in one patient.

These findings do not justify the common clinical notion of regarding intramuscular injections as a frequent cause of serum CK elevation. It is concluded that high CK serum values in a patient with chest pain should always be considered with utmost suspicion, disregarding the possible effects of a previous intramuscular injection.
\end{abstract}

\section{Introduction}

It is an accepted fact that a significant rise of serum creatine kinase (CK) activity may follow intramuscular (i.m.) injections (Braunwald \& Alpert, 1983; Hurst, 1982; Nevins et al., 1973). This can lead to the erroneous diagnosis of myocardial infarction in a patient who has been given an i.m. injection for chest pain of non-cardiac origin.

Although various drugs have been reported to cause an increase in serum CK there is not enough information available to predict when and in what pattern a given i.m. injection will result in CK elevation (Cohen, 1972; Meltzer et al., 1970; Nevins et al., 1973). This study was undertaken to investigate the frequency and kinetics of serum CK elevation following intramuscular administration of drugs commonly used in patients admitted for chest pain. Our observations indicate that significant elevation of serum CK after i.m. injections in a common clinical setting is rare.

\section{Materials and methods}

Forty-four adult patients (23 male and 21 female, age $40-75 y$ ) who were hospitalized in a medical ward for

Correspondence: F. Konikoff, M.D., Dept. of Internal Medicine E, Beilinson Medical Center, Petah-Tiqva, 49 100, Israel.

Accepted: 5 March 1985 non-cardiac reasons, were selected for the study. Only patients who had baseline $\mathrm{CK}$ values within the normal range (males $<137 \mathrm{IU} / 1$, females $<118 \mathrm{IU} / \mathrm{l}$ ), as measured less than $24 \mathrm{~h}$ before the injection, were included. All patients who were excluded because of high baseline values were found to have an obvious cause for the elevated CK activity (other than i.m. injections). An informed consent was obtained from all participants. Each patient received a single i.m. injection of one of the following drugs in a gluteal muscle: diazepam $\left(\right.$ Valium $\left.^{\mathrm{R}}\right)$, dipyrone $\left(\right.$ Optalgin $\left.^{\mathrm{R}}\right)$, metoclopramide (Pramine ${ }^{R}$ ), pethidine, pentazocine $\left(\right.$ Talwin $^{R}$ ) and procaine penicillin. These drugs were chosen because of their frequent intramuscular use in patients complaining of chest discomfort - not necessarily of cardiac origin. The doses and volumes of the injections are shown in Table 1 . The injections were

Table I Intramuscular injections given

\begin{tabular}{lcc}
\hline Drug & Dose & Volume $(\mathrm{ml})$ \\
\hline Diazepam & $5 \mathrm{mg}$ & 1 \\
Dipyrone & $1 \mathrm{~g}$ & 2 \\
Metoclopramide & $10 \mathrm{mg}$ & 2 \\
Pethidine & $75 \mathrm{mg}$ & 1.5 \\
Pentazocine & $30 \mathrm{mg}$ & 2 \\
Procaine penicillin & $1.2 \times 10^{6} \mathrm{U}$ & 4.5 \\
\hline
\end{tabular}


administered with a 21-gauge needle by an experienced nurse. No subsequent i.m. injections were given to the subjects for at least $3 \mathrm{~d}$. Simultaneous myocardial injury was excluded in all patients by a daily clinical and electrocardiographic evaluation.

Serum CK activity was measured at 1, 6, 12, 24, 48 and $72 \mathrm{~h}$ after the injection. A u.v.-method was used employing a glutathione activated BMC-kit ('CPKactivated No. 124184') with creatine phosphate as substrate (Forster et al., 1974). The measurements were done using a Gemsaec centrifugal analyser (Electronucleonics) at $37^{\circ} \mathrm{C}$. Daily quality control was maintained using BMC Precinorm and Precipath assayed controls. For serum samples (stored at $-18^{\circ} \mathrm{C}$ ) with elevated CK activity an electrophoretic measurement of CK-isoenzymes was subsequently performed (on cellulose acetate), applying the Helena CK isoenzyme electrophoresis procedure based on the method reported by Trainer \& Gruenig (1968).

\section{Results}

The incidence of increased CK activity after the injections is shown in Table II. Only 3 out of the 44 patients had elevation of serum CK above normal during the follow-up period of $72 \mathrm{~h}$. These subjects had received diazepam, dipyrone or penicillin. Table III summarizes the total CK and CK-isoenzymes for these patients. The serum CK activities for all other patients are shown in Table IV.

In all instances the increase of CK activity was primarily due to elevation of the MM-isoenzyme fraction, although one patient (after dipyrone) who had the highest total CK activity also had a rise of the MB-fraction above normal ( $<15 \mathrm{IU} / 1)$. No elevation of the BB-fraction was observed.

The injections that did raise CK were not found to
Table II Number of patients with elevated CK following i.m. injections

\begin{tabular}{lcc}
\hline Drug & $\begin{array}{c}\text { No. of } \\
\text { patients }\end{array}$ & $\begin{array}{c}\text { No. with } \\
\text { elevated } C K\end{array}$ \\
\hline Diazepam & 8 & 1 \\
Dipyrone & 9 & 1 \\
Metoclopramide & 14 & - \\
Pethidine/pentazocine & 6 & - \\
Penicillin & 7 & 1 \\
\hline Total & 44 & 3
\end{tabular}

have any specific common denominator, such as $\mathrm{pH}$, osmolality, volume or a particular solvent.

\section{Discussion}

Previous studies have documented elevation of serum CK activity following i.m. injections (Knirsch \& Gralla, 1970; Meltzer et al., 1970; Sidell et al., 1974). The incidence of this association has been reported to be $45 \%$ or more after drugs that included chlorpromazine, barbiturates, atropine, diazepam, chlordiazepoxide, pralidoxime chloride, digoxin, frusemide, ampicillin, carbenicillin, morphine, pethidine, dexamethazone, nandrolone decanoate and normal saline (Greenblatt et al., 1973; Nevins et al., 1973; Ma et al., 1981; Meltzer et al., 1970). These reports have led authors of textbooks on internal medicine (Braunwald \& Alpert, 1983), cardiology (Hurst, 1982) and others (Cacace, 1972) to conclude that i.m. injections are an important cause of serum CK elevation. The aim of this study was to evaluate prospectively the incidence and pattern of CK elevation following i.m. injections

Table III Sequential results of 3 patients with elevated total CK values

\begin{tabular}{|c|c|c|c|c|c|c|c|}
\hline & Baseline & $1 h$ & $6 h$ & $12 h$ & $24 h$ & $48 h$ & $72 h$ \\
\hline $\begin{array}{l}\text { Dipyrone } \\
\text { (BB, MB, } \\
\text { MM) }\end{array}$ & $\begin{array}{c}66^{*} \\
(-, 8,58) \dagger\end{array}$ & $\begin{array}{c}88 \\
(-, 14,74)\end{array}$ & $\begin{array}{c}209 \\
(-, 21,188)\end{array}$ & $\begin{array}{c}236 \\
(-, 28,208)\end{array}$ & $\begin{array}{c}179 \\
(-, 39,140)\end{array}$ & $\begin{array}{c}112 \\
(-, 17,95)\end{array}$ & $\begin{array}{c}66 \\
(-, 9,57)\end{array}$ \\
\hline $\begin{array}{l}\text { Diazepam } \\
\text { (BB, MB, } \\
\text { MM) }\end{array}$ & $\begin{array}{c}36^{*} \\
(-,-, 36) \dagger\end{array}$ & $\begin{array}{c}72 \\
(-,-, 72)\end{array}$ & $\begin{array}{c}167 \\
(-,-, 167)\end{array}$ & n.p. & $\begin{array}{c}139 \\
(-, 13,126)\end{array}$ & $\begin{array}{c}127 \\
(-,-, 127)\end{array}$ & $\begin{array}{c}81 \\
(-, 15,66)\end{array}$ \\
\hline $\begin{array}{l}\text { Pencillin } \\
\text { (BB, MB, } \\
\text { MM) }\end{array}$ & $\begin{array}{c}52^{*} \\
(-.6,46) \dagger\end{array}$ & $\begin{array}{c}103 \\
(-, 12,91)\end{array}$ & $\begin{array}{c}115 \\
(-, 15,100)\end{array}$ & $\begin{array}{c}148 \\
(-, 13,135)\end{array}$ & $\begin{array}{c}104 \\
(-,-, 104)\end{array}$ & $\begin{array}{c}74 \\
(-, 7,67)\end{array}$ & $\begin{array}{c}54 \\
(-, 10,44)\end{array}$ \\
\hline
\end{tabular}

* Total CK (normal: males $<137$, females $<118$ ).

$+\mathrm{CK}$ isoenzymes (normal: $\mathrm{BB}-0, \mathrm{MB}<15, \mathrm{MM}<137$ ).

All values are in international units (IU/l).

n.p.: not performed. 
Table IV Mean CK values for subjects with no CK elevation

\begin{tabular}{lcccccccc}
\hline Drug & Baseline & $1 \boldsymbol{h}$ & $6 \boldsymbol{h}$ & $12 \boldsymbol{h}$ & $24 \boldsymbol{h}$ & $48 \boldsymbol{h}$ & $72 \boldsymbol{h}$ \\
\hline Diazepam & 37 & 32 & 46 & 56 & 40 & 48 & 34 & \\
Dipyrone & 36 & 38 & 39 & 41 & 46 & 41 & 29 \\
Metoclopramide & 44 & 38 & 34 & 45 & 38 & 33 & 25 \\
Pethidine/pentazocine & 32 & 37 & 31 & 25 & 31 & 34 & 25 & 34 \\
Penicillin & 38 & 41 & 40 & 32 & 30 & 27 & \\
\hline
\end{tabular}

Values are in IU/1.

in a common clinical setting. We observed increased serum CK activity in only 3 out of 44 patients, each of whom received a different drug.

Most previous investigations have involved young healthy volunteers or laboratory animals (Sidell et al., 1974; Klein et al., 1973). We studied patients hospitalized in a medical ward with ages ranging from 40 to $75 \mathrm{y}$ for whom the prompt and correct diagnosis of myocardial injury is of major clinical importance. The older age and the smaller muscle mass in this age group may explain why the incidence and amount of CK elevation was found to be significantly lower in our study. There are also other variables that could account for the differing results, such as the chemical composition, dose, volume and concentration of the drugs injected (Sidell et al., 1974). However, we tried to solve the common diagnostic problem of a patient in a medical ward with chest pain who has received an i.m. injection on admission or before the correct diagnosis has been made. This study involves an adult patient population with drugs and doses common to everyday clinical practice, leading us to conclude that elevation of CK following i.m. injection in these specific circumstances, which are of clinical interest, is rare.

\section{References}

APPLE, F.S., ROGERS, M.A., SHERMAN, W.M. \& IVY, J.L. (1984). Comparison of serum creatine kinase and creatine kinase MB activities post marathon race versus post myocardial infarction. Clinica Chimica Acta, 138, 111.

BRAUNWALD, E. \& ALPERT, J.S. (1983). Acute myocardial infarction. In Harrison's Principles of Internal Medicine, Petersdorf, R.G., Adams, R.D., Braunwald, E., Isselbacher, K.J., Martin, J.B. \& Wilson, J.D. (eds) 10th edition, p. 1433. McGraw Hill Inc.: New York.

CACACE, L. (1972). Elevated serum CPK after drug injections. New England Journal of Medicine, 287, 309.

COHEN, L. (1972). CPK test - effect of intramuscular injection in myocardial infarction. Journal of the American Medical Association, 219, 625.

FORSTER, G., BERNT, E. \& BERGMEYER, H.U. (1974). Creatine kinase. In Methods of Enzymatic Analysis, Bergmeyer, H.U. (ed.), 2nd edition, vol. 2, p. 784. Verlag
The increased CK activity in our 3 subjects was primarily caused by a rise of the MM-isoenzyme fraction. However, in one subject a significant associated rise of the MB-fraction was seen. This observation is consistent with reports from previous studies (Ma et al., 1981), and with increased serum CK-MB activity reported in other situations compatible with skeletal muscle injury, such as marathon running (Apple et al., 1984). Although ours is a small sample; the observation indicates that measurement of CK isoenzymes to differentiate between myocardial or skeletal origin in the above circumstances may be of limited practical value. This is a point which calls for further investigation.

It is concluded that elevated serum CK values in a patient with chest pain should always be considered with utmost suspicion, disregarding the possible effects of a previous i.m. injection.

\section{Acknowledgement}

The authors are grateful to Dr D. Harell from the Department of Clinical Biochemistry for her kind assistance with the biochemical assays.
Chemie Weinheim and Academic Press: N.Y. and London.

GREENBLATT, D.J., DUHME, D.W. \& KOCH-WESER, J. (1973). Pain and CPK elevation after intramuscular digoxin. New England Journal of Medicine, 288, 689.

HURST, J.W. (1982). In The Heart, Arteries and Veins, p. 1050 . McGraw Hill: New York.

KLEIN, M.S., SHELL, W.E. \& SOBEL, B.E. (1973). Serum creatine phosphokinase (CPK) isoenzymes following intramuscular injections, surgery and myocardial infarction. Experimental and clinical studies. Cardiovascular $R e$ search, 7, 412.

KNIRSCH, A.K. \& GRALLA, E.J. (1970). Abnormal serum transaminase levels after parenteral ampicillin and carbenicillin administration. New England Journal of Medicine, 282, 1081.

MA, K.W., BROWN, D.C., STEELE, B.W. \& FROM, A.H.L. 
(1981). Serum creatine kinase MB isoenzyme activity in long-term hemodialysis patients. Archives of Internal Medicine, 141, 164.

MELTZER, H.Y., MROZAK, S. \& BOYER, M. (1970). Effect of intramuscular injections on serum creatine phosphokinase activity. American Journal of the Medical Sciences, 259, 42.

NEVINS, M.A., SARAN, M., BRIGHT, M. \& LYON, L.Y. (1973).

Pitfalls in interpreting serum creatine phosphokinase activity. Journal of the American Medical Association, 224, 1382.
SIDELL, F.R., CULVER, D.L. \& KAMINSKIS, A. (1974). Serum creatine phosphokinase activity after intramuscular injection. The effect of dose, concentration and volume. Journal of the American Medical Association, 229, 1894.

TRAINER, T.D. \& GRUENIG, D. (1968). A rapid method for the analysis of creatine phosphokinase isoenzymes. Clinica Chimica Acta, 21, 151. 